\title{
The Murine Situs Inversus Viscerum (iv) Gene Responsible for Visceral Asymmetry Is Linked Tightly to the Igh-C Cluster on Chromosome 12
}

\author{
Andrzej J. Hanzlik, Michael Binder, $†$ William M. Layton, $\dagger$ lucy Rowe, $\ddagger$ Mary Layton, $\dagger$ \\ Benjamin A. Taylor, $\ddagger$ Malgorzata M. Osemlak, * Julia E. Richards, $\S$

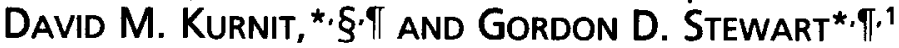 \\ Departments of $\$ Pediatrics and §Human Genetics, and *Howard Hughes Medical Institute, University of Michigan School of \\ Medicine, Ann Arbor, Michigan 48109; †Department of Anatomy, Dartmouth Medical School, Hanover, \\ New Hampshire 03756; and $¥$ The Jackson Laboratory, Bar Harbor, Maine 04609
}

Received December 22, 1989; revised March 8, 1990

The $i v$ gene controls left-right determination during murine organogenesis. To map this gene, we analyzed backcross progeny produced by mating (C57BL/6J $\times \mathrm{MEV} / \mathrm{Ty}) \mathrm{F}_{1-i v /+}$ heterozygotes to $\mathrm{C57BL} / 6 \mathrm{~J}-i v$ homozygotes. Hybridization of a murine ecotropic virus probe and several homeotic box gene probes coupled with analysis of dominant visible markers enabled us to exclude the iv locus from much of the mouse genome. Spurred by a recent report that mapped the $i v$ gene to mouse chromosome 12 which was not excluded by our previous work, we used the polymerase chain reaction on our larger cohort to determine that the $i v$ gene is indeed linked tightly to the $I g h-C$ locus on this chromosome: we observed 0/156 recombinants between the iv and $I g h-C$ loci. Combining data from the two studies demonstrates that the murine iv gene is close (1/201 recombinants) to the $I g h-C$ cluster on chromosome 12 . (c) 1990 Academic Press, Inc.

\section{INTRODUCTION}

Single gene defects in the mouse and human can result in situs inversus. In the mouse, this trait is caused by the autosomal recessive gene iv (Hummel and Chapman, 1959). Approximately $50 \%$ of iv/iv mice show situs inversus, and the situs of offspring is independent of that of their parents. This rate of situs inversus in iv/iv mice is not affected by genetic background (Layton, 1976). Because of these peculiarities in the mode of inheritance, it has been hypothesized that the phenotype results from the loss of control of

\footnotetext{
${ }^{1}$ To whom reprint requests should be addressed at Howard Hughes Medical Institute, University of Michigan School of Medicine, 1150 W. Medical Center Dr., MSRB I, Room 3520, Ann Arbor, MI 481090650.
}

the development of the normal sense of bilateral asymmetry (situs solitus), allowing situs to be determined by chance (Layton, 1976). This is consistent with a stochastic model for morphogenesis (Kurnit et al., 1987).

The phenotype of $i v / i v$ mice, besides situs inversus, includes other disturbances in situs that can be regarded as partial visceral reversal in nonreversed mice or partial visceral nonreversal in reversed mice. The term "heterotaxia" is used for these abnormalities of visceral situs. Heterotaxia is found in about $40 \%$ of $i v /$ iv mice and occurs with equal frequency in mice with situs solitus and situs inversus. These affected mice show a high incidence of severe heart malformations, many of which are lethal in the perinatal period (Layton, 1978; Layton and Manasek, 1980; Van Praagh et al., 1980). This mirrors the situation in man, where cardiac anomalies have been associated with situs inversus and other disturbances of situs such as polysplenia and asplenia (Ivemark, 1955; Arnold et al., 1983). To understand how laterality determination impacts organogenesis (including cardiogenesis), we need to determine how gene expression on the eighth gestational day in the mouse (when left-right asymmetry first becomes evident) determines situs (M. L. Van Keuren, W. M. Layton, R. Iacob, and D. M. Kurnit, unpublished data). Here, we confirm and extend earlier work (Brueckner et al., 1989) that maps the $i v$ gene to mouse chromosome 12 .

\section{MATERIALS AND METHODS}

\section{Mouse Strains}

MEV/Ty mice (henceforth abbreviated as MEV; Jackson Laboratory) bear murine leukemia virus proviruses on chromosomes $1,2,3,5,7$ (two distinct sites), 
$8,9,10,11,18$, and 19 (Taylor and Rowe, 1989). These mice also carry three dominant visible markers: hammer-toe $(\mathrm{Hm})$, steel $(\mathrm{Sl})$, and caracul-J $\left(\mathrm{Ca}^{J}\right)$ on chromosomes 5,10 , and 15 , respectively.

C57BL/6J-iv/iv (henceforth abbreviated as B6-iv) mice were the product of 11 cycles of cross-intercross mating and selection of $\mathrm{C} 57 \mathrm{BL} / 6 \mathrm{~J}$ mice with $i v / i v$ mice, starting with a noninbred $i v / i v$ mouse (Hummel and Chapman, 1959). These B6-iv mice subsequently underwent at least six generations of brother-sister mating.

$\mathrm{F}_{1}$ hybrids were constructed by mating $\mathrm{B} 6-i v \times \mathrm{MEV}$ mice. The resulting $\mathrm{F}_{1} \mathrm{~B} 6-i v / \mathrm{MEV}$ heterozygotes, bearing one or more of the dominant visible mutations, were backcrossed to B6-iv mice. Homozygous (iv/iv) backcross mice were identified by autopsy examination for visceral reversal and/or heterotaxia. In addition to complete situs inversus, azygos-posterior vena cava continuity and preduodenal portal vein were used as criteria for homozygosity at the iv locus. Abnormalities in liver lobation or in gut rotation (which can occur independently of the iv mutation) were not used as criteria. In some cases, the autopsies were done on adult or weanling mice. The livers, spleens, and kidneys were removed for preparation of DNA from adult or weanling backcross mice with reversed viscera and/or heterotaxia. At the time of autopsy, these mice were scored for the dominant visible markers $\left(\mathrm{Hm}, \mathrm{Sl}\right.$, and $\left.C a^{J}\right)$. In other cases, newborn animals were used. In these cases, the mice were autopsied but could not be scored for dominant visible markers, and the entire animal was used as a source of DNA.

\section{Isolation of DNA}

DNA was isolated from 1-2 $\mathrm{g}$ of frozen tissue, corresponding to livers and spleens from parental, $F_{1}$, and backcross mice, or from whole newborn backcross mice. The frozen tissue was powdered in liquid nitrogen, then shaken gently overnight to deproteinize at $55^{\circ} \mathrm{C}$ in 20 $\mathrm{ml}$ of $0.024 M$ EDTA, $0.075 M \mathrm{NaCl}, 0.5 \%$ (w/v) sodium dodecyl sulfate, and $0.0025 \%(\mathrm{w} / \mathrm{v})$ proteinase $\mathrm{K}$. Nucleic acids were precipitated by adding $10 \mathrm{M} \mathrm{NH}_{4} \mathrm{Ac}$ to a final concentration of $2 M$, followed by an equal volume of isopropanol. Precipitates were dissolved in $0.024 M$ EDTA and $0.075 M \mathrm{NaCl}$. Sodium dodecyl sulfate was added to $0.5 \%(\mathrm{w} / \mathrm{v})$ and proteinase $\mathrm{K}$ to $0.0025 \%(\mathrm{w} / \mathrm{v})$. The solution was deproteinized again by shaking with an equal volume of phenol, and DNA was precipitated with 2 vol of ethanol. The resulting pellet was resuspended in $5 \mathrm{~m} M$ Tris and $0.1 \mathrm{mM}$ EDTA, pH 7.4.

\section{Filter Hybridization}

DNA was digested with restriction enzymes (New England Biolabs) in buffers recommended by the man- ufacturer. Following digestion, the products were electrophoresed on an $0.8 \%$ agarose gel (SeaKem, FMC) and transferred to nylon filters (Plasco). Filter hybridization, washing, and exposure were detailed previously (Neve et al., 1986).

\section{Polymerase Chain Reaction (PCR)}

One microgram of genomic DNA was amplified using PCR (Saiki et al., 1985). The buffer for PCR amplification was $50 \mathrm{mM} \mathrm{KCl}, 10 \mathrm{~m} M$ Tris (pH 8.3), $1.5 \mathrm{mM}$ $\mathrm{MgCl}_{2}$, and $200 \mu \mathrm{mol}$ of each deoxynucleotide plus $0.01 \%(\mathrm{w} / \mathrm{v})$ gelatin. Each reaction contained 2.5 units of Taq polymerase (gift of Dr. D. Engelke). The primers used for amplification were GA1 (5'-TAGAGACCATTACACCTAGATTGGAAGACT-3') and GA2 (5'CTATTCTCTATGTCCCTATTCTGTATTCTG-3'), 30-mers synthesized on an Applied Biosystems 380B DNA synthesizer. PCR products were visualized with ethidium bromide following electrophoresis on $2 \% \mathrm{Nu}$ sieve $/ 0.5 \%$ SeaKem agarose gels. $\phi$ X174 DNA digested with HaeIII was used as a size marker. DNA was amplified using 35 cycles of amplification, with each cycle consisting of $90 \mathrm{~s}$ at $94^{\circ} \mathrm{C}, 90 \mathrm{~s}$ at $55^{\circ} \mathrm{C}$, and $120 \mathrm{~s}$ at $72^{\circ} \mathrm{C}$. After the final cycle, an additional extension for $7 \mathrm{~min}$ at $72^{\circ} \mathrm{C}$ was performed.

\section{RESULTS}

To screen for crossovers between markers and the iv gene, we backcrossed an $\mathbf{F}_{1} \mathbf{B} 6-i v \times \mathrm{MEV}$ heterozygote to a B6-iv homozygote. We chose this breeding scheme to take advantage of the placement of multiple murine leukemia virus proviruses into the genome of the MEV mouse (Taylor and Rowe, 1989). The incidence of situs inversus in the backcross mice at birth was $19.8 \%(164 / 830)$, whereas the predicted incidence is $25 \%$ (assuming $50 \%$ penetrance). The incidence of the $i v$ phenotype at autopsy was $29.0 \%(214 / 737)$, whereas the predicted incidence is $35 \%$ (based on seeing situs inversus and/or heterotaxia at autopsy). These significant differences between observed and predicted values presumably reflect prenatal and perinatal mortality due to heart malformations. No sex preference was observed, with an essentially equal number of phenotypically reversed offspring born to iv/iv dams (with $+/ i v$ sires) and $+/ i v$ dams (with iv/iv sires).

Using this breeding scheme, it was possible to sweep a substantial portion of the murine genome with a single Southern (1975) blot using a radiolabeled murine leukemia provirus probe (Taylor and Rowe, 1989). Figure 1 shows an example of a representative Southern blot, demonstrating independent assortment of the $i v$ gene with proviruses on any of 10 mouse autosomes. Using $\chi^{2}$ analysis, we saw no evidence of linkage between the $i v$ gene and these retrovirus markers in MEV 


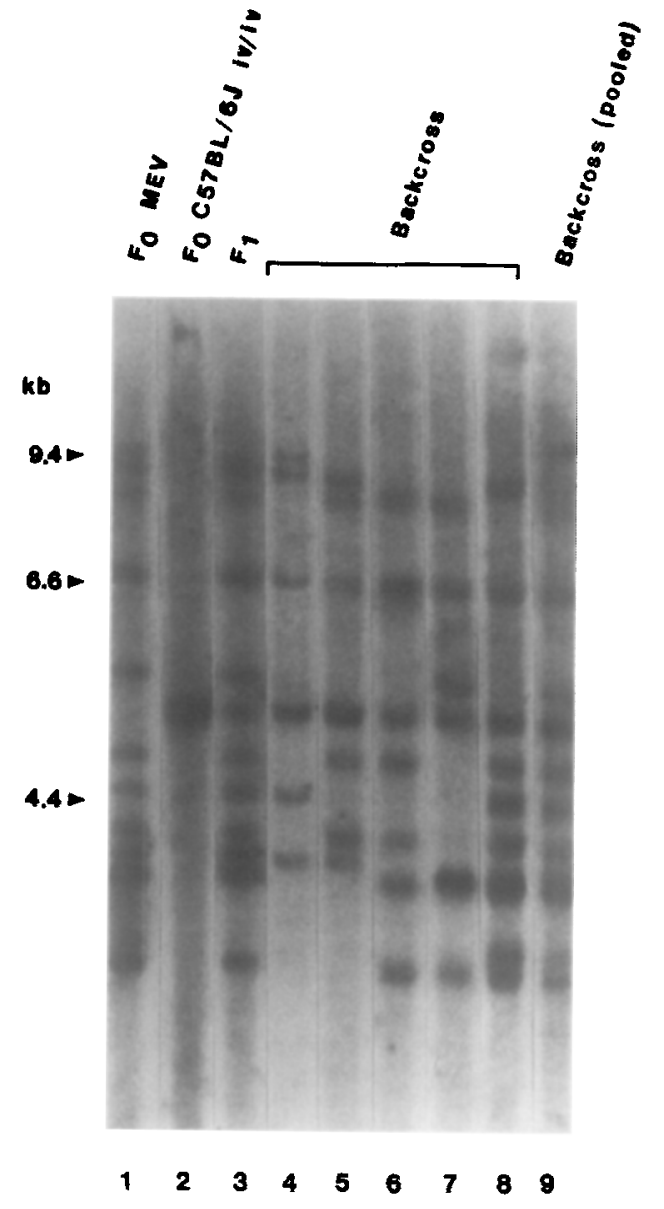

FIG. 1. Lack of linkage between $i v$ and ecotropic murine leukemia proviruses. PvulI-digested murine genomic DNA was hybridized with the radiolabeled ecotropic murine leukemia provirus probe, pEcB4. (1) MEV mice; (2) B6-iv mice; (3) $\mathrm{F}_{1}$ heterozygotes resulting from the mating of B6-iv mice with MEV mice; (4-8) backcross mice resulting from the mating of $\mathrm{B} 6-i v / \mathrm{MEV}$ heterozygotes (lane 3) to B6-iv homozygotes (lane 2); (9) Pooled DNA from $156 \mathrm{iv} / \mathrm{iv}$ (reversed) mice resulting from mating of $\mathrm{B} 6-i v / \mathrm{MEV}$ heterozygotes to B6-iv homozygotes. The lowest molecular weight bands correspond to loci that had not been made homozygous at the time the cross was established. One provirus insertion came from $\mathrm{B} 6$, and the remainder came from MEV.

(chromosomal locations known (Taylor and Rowe, 1989)) or in B6 (chromosomal location unknown) mice. The evidence against linkage is also demonstrated in lane 9 of Fig. 1: the presence of all retroviral bands at the same intensity demonstrates that none of these bands is linked to the $i v$ mutation. In addition, we did not detect linkage between the $i v$ gene and the visible markers $\mathrm{Hm}, \mathrm{Sl}$, or $\mathrm{Ca}^{J}$. Not having found linkage to the chromosomes defined by these markers, we endeavored to find linkage to murine homeobox probe $H o x$ 1.1 and engrailed probes En-1 and En-2 (Colberg-Pauley et al., 1985; Joyner et al., 1985). This attempt was based on the consideration that murine homeobox genes direct early events in morphogenesis, including the generation of axes during development. No linkage was found. Taken together, this work excluded the $i v$ gene from more than half of the murine autosomal genome (Colberg-Pauley et al., 1985; Joyner et al., 1985; Taylor and Rowe, 1989).

Having excluded much of the murine genome, we learned that another group had obtained linkage between the $i v$ gene and several markers on chromosome 12 (Brueckner et al., 1989). The closest linkage was observed between the $i v$ gene and the murine immunoglobulin heavy chain $(I g h-C)$ locus on the distal end of this autosome.

Two recent reports documented that short stretches of variable $d(A, C): d(G, T)$ sequences abound in $5 \times 10^{4}$ copies of a mammalian (human) genome (Weber and May, 1989; Litt and Luty, 1989). Detection of this fine structure variability required that oligonucleotides surrounding the oligo $(d(A, C): d(G, T))$ stretch be synthesized. Following amplification of the intervening region using the PCR (Saiki et al., 1985), the size of the amplified region between the oligonucleotide probes could be determined directly on a fine-pore agarose gel. In this manner, it was feasible to document small changes in nucleotide sequence length that resulted from variation in the number of $(A, C)$ reiterations.

The sequence of the murine $I g h-C \delta$ intron switch region (Richards, 1983) documented the existence therein of an oligo $(d(A, C): d(G, T))$ region immediately $5^{\prime}$ to an oligo $(\mathrm{d}(\mathrm{T}, \mathrm{C}): \mathrm{d}(\mathrm{G}, \mathrm{A}))$ region. Working from this sequence, we constructed the oligonucleotides GA1 and GA2 that flank this oligo(d(A,C):d(G,T)) + oligo(d(T,C):d(G,A)) region. The length of polynucleotide synthesized following PCR amplification of this sequence (including the oligo $(\mathrm{d}(\mathrm{A}, \mathrm{C}): \mathrm{d}(\mathrm{G}, \mathrm{T})$ ) + oligo $(d(T, C): d(G, A))$ repeats) differed between B6-iv and MEV mice (Fig. 2). As a result, this methodology was used to distinguish the B6 from the MEV genome at the Igh-C locus. We used this methodology directly on our backcross animals. One allele in the backcross generation came from each $F_{1}$ parent; i.e., one allele came from the $\mathrm{F}_{1}(\mathrm{~B} 6-i v \times \mathrm{MEV})$ heterozygote and one allele came from the B6-iv homozygote.

DNA was isolated and PCR-amplified (Materials and Methods) from 156 backcross animals that showed the reversed (iv/iv) phenotype. The MEV amplification product was larger than that of the $\mathrm{B} 6$ (Fig. 2), due likely to the existence of more oligo $(d(A, C): d(G, T))$ and/or oligo(d(T,C):d(G,A)) repeats in the MEV genotype (Weber and May, 1989; Litt and Luty, 1989). In all 156 backcross animals, we observed concordance between the reversed iv phenotype and homozygosity for the shorter B6 genotype. This enables us to state that the iv gene and the Igh-C locus cosegregated in 156 meiotic events, demonstrating tight linkage between these two loci. 


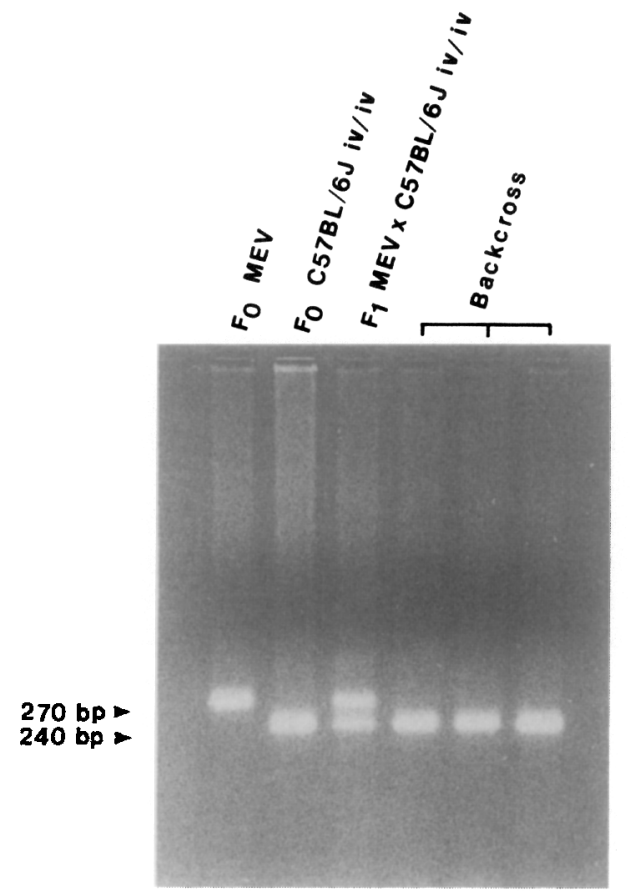

FIG. 2. Determination of linkage between $i v$ gene and the murine immunoglobulin heavy chain locus, detected using the polymerase chain reaction (PCR). Using the oligonucleotides GA1 and GA2 (Materials and Methods), the intervening region was amplified via PCR (18). This agarose gel distinguished between B6 and MEV alleles, with the MEV allele being longer than the B6 allele. All 156 $i v / i v$ homozygotes resulting from the backcross analyzed by this methodology were also homozygous for the shorter allele at the Igh$C$ locus, demonstrating tight linkage between the $i v$ locus and the Igh-C locus.

To investigate the usefulness of this polymorphism in a variety of mouse strains, we determined the size of the PCR-amplified DNA fragment in these strains. We found at least three groups (data not shown):

Group 1: C57BL/6J, B6-iv, SWV, PL/J, SJL/J, $\mathrm{C} 3 \mathrm{H} / \mathrm{HeJ}, \mathrm{SWR} / \mathrm{J}$, and BALB/cHuCol- $i v$.

Group 2: A/J and DBA/2J.

Group 3: BALB/cByJ, AKR/J, C58/J, 129/J, MEV/ 1Ty, CAST/Ei, NZB/B1NJ, and C57L/J.

Both of the iv strains belong to Group 1, as does the congenic line of one of the strains $(\mathrm{C} 57 \mathrm{BL} / 6 \mathrm{~J})$ but not the other (BALB/cByJ). The difference between $\mathrm{BALB} / \mathrm{cHuCol}-i v$ and BALB/cByJ is consistent with the surmise that at least part of the Igh-C region has been cotransferred along with $i v$ during backcrossing. Other interpretations (e.g., mutation) are possible, but less likely. The failure to see a difference between C57BL/6J- $i v$ and the C57BL/6J congenic strain could have resulted from iv having arisen in cis with the Group 1 haplotype at $I g h-C$ and does not imply that iv and Igh-C have recombined in the derivation of this strain. (The $i v$ mutation was first detected on a mixed genetic background (Hummel and Chapman, 1959).)
This polymorphism represents a useful marker for the $I g h-C$ region in a variety of mouse strains. Higher resolution gels may further subdivide these groups.

\section{DISCUSSION}

While use of the MEV linkage testing stock mouse enables one to sweep a large proportion of the murine genome rapidly (Taylor and Rowe, 1989), this strategy did not enable us to localize the iv gene. Nevertheless, this strategy did enable us to eliminate a large portion of the murine genome expeditiously. Although the use of the MEV stock did not lead to immediate mapping of the $i v$ gene, it still represents a powerful method for the mapping of a previously unassigned murine gene. We also did not detect linkage between the $i v$ locus and a number of cloned mouse homeobox genes. Fortunately, the availability of an informative polymorphism closely linked to the $i v$ gene made the backcross animals, generated in the B6-iv/MEV mating, useful for this study.

Variability of oligo(d(A,C):d(G,T)) can be used as a genetic marker, and indeed has been utilized for this purpose (Dean et al., 1990). In our case, we do not know whether the observed variability stems from differences in the quantity of these sequences and/or the adjacent oligo $(\mathrm{d}(\mathrm{T}, \mathrm{C}): \mathrm{d}(\mathrm{G}, \mathrm{A}))$ sequences. In any event, there is no inherent difference between this technique and performing linkage analysis by determining the segregation of DNA differences detected by Southern blotting (Kan and Dozy, 1978). Advantages of the PCR-based technique include rapidity, a need for small amounts of genomic DNA, and lack of requirement for radioisotope handling. This study utilized these advantages to evaluate rapidly the reported linkage between the $i v$ gene and the Igh-C locus. This simple typing methodology will facilitate the identification of rare crossovers in this region.

As a result of the cosegregation of the $i v$ genotype and the $I g h-C$ immunoglobulin heavy chain locus, we concur with previous work that mapped $i v$ to murine chromosome 12 (Brueckner et al., 1989). These workers were fortunate in that they observed linkage after scanning only a small portion of the genome. Using PCR-based methodology to detect variation of $(\mathrm{CA})_{n}$ repeats, we confirmed efficiently the linkage detected by Brueckner et al. (1989) using conventional restriction fragment length polymorphisms. Our formal lod score favoring linkage between $i v$ and the $I g h-C$ locus on chromosome 12 is 47 . Using our larger cohort, it appears that the iv gene is threefold closer to the Igh$C$ locus than Brueckner et al. (1989) found. Combining the data from the two studies, we estimate that the iv locus is about $0.5 \mathrm{cM}$ from Igh-C. The upper $95 \%$ confidence limit of the map distance (combining both data sets) is $2.4 \mathrm{cM}$. 
The finding that the Igh-C locus on murine chromosome 12 is close to the $i v$ locus points to a genomic strategy to clone the iv gene. Assuming that $0.5 \mathrm{cM}$ is equivalent to $10^{6}$ base pairs on the average in mouse, this places the $i v$ gene within 5 million base pairs of the $I g h-C$ region. Of course, the actual physical distance between the $i v$ gene and the Igh-C locus depends on both the true recombination distance and the precise correlation between genetic and physical distances in this part of the genome. Nevertheless, it is clear that the $I g h-C$ locus and the $i v$ gene are linked closely. Genomic strategies to cover long stretches of a mammalian genome rapidly (Rommens et al., 1989) are now in order.

\section{ACKNOWLEDGMENTS}

This work was supported by NIH Grants HL37703 and CA33093 and by March of Dimes Grant 6-501. The NIH is not responsible for the contents of this publication nor do the contents necessarily represent the official views of that agency. D.M.K. is an Investigator and G.D.S. is an Associate, Howard Hughes Medical Institute. Drs. P. Gruss and G. Martin provided murine homeobox and engrailed probes.

\section{REFERENCES}

1. ARnold, G. L., Bixler, D., AND Girod, D. (1983). Probable autosomal recessive inheritance of polysplenia, situs inversus and cardiac defects in an Amish family. Amer. J. Med. Genet. 16: $35-42$.

2. BRUeckner, M., D'EustachIo, P., AND HORWICH, A. L. (1989). Linkage mapping of a mouse gene, iv, that controls left-right asymmetry of the heart and viscera. Proc. Natl. Acad. Sci. USA 86: 5035-5038.

3. Colberg-Pauley, A. M., Voss, S. D., Chowdhury, K., STEWART, C. L., WAGNER, E. F., AND Gruss, P. (1985). Clustered homeo boxes are differentially expressed during murine development. Cell 43: 39-45.

4. Dean, M., Drumm, M. L., Stewart, C., Gerrard, B., Perry, A., Hidaka, N., Cole, J. L., Collins, F. S., AND IANNuzZi, M. C. (1990). Proc. Natl. Acad. Sci. USA, in press.

5. HUMMEL, K. P., AND CHAPMAN, D. B. (1959). Visceral inversion and associated anomalies in the mouse. J. Hered. 50: 9-13.

6. IVEMARK, I. (1955). Implications of agenesis of the spleen on the pathogenesis of conotruncus anomalies in childhood. Acta Paediatr. Scand. 44(Suppl. 104): 590-592.

7. Joyner, A. L., KornberG, T., Coleman, K. G., Cox, D. R., AND MARTIN, G. R. (1985). Expression during embryogenesis of a mouse gene with sequence homology to the Drosophila engrailed gene. Cell 43: 29-37.

8. KAN, Y. W., AND DoZY, A. M. (1978). Polymorphism of DNA sequence adjacent to human $\beta$-globin structural gene: Relationship to sickle mutation. Proc. Nath Acad. Sci. USA 75: 5631-5635.

9. KURNIT, D. M. (1979). Evolution of sickle variant gene. Lancet 1: 104.

10. KuRnit, D. M., LAYToN, W. M., AND MATThysSe, S. (1987). Genetics, chance, and morphogenesis. Amer. J. Med. Genet. 41: 979-995.

11. LAYTON, W. M., JR. (1976). Random determination of a developmental process. J. Hered. 67: 336-338.

12. LAYTON, W. M., JR. (1978). Heart malformations in mice homozygous for a gene causing situs inversus. Birth Defects: Orig. Art. Series 14(7): 277-293.

13. LAYTON, W. M., JR., AND MANASEK, F. J. (1980). Cardiac looping in early iv/iv mouse embryos. In "Etiology and Morphogenesis of Congenital Heart Disease" (R. Van Praagh and A. Takao, Eds.), pp. 109-126, Futura, Mt. Kisco, NY.

14. LITT, M., AND LUTY, J. A. (1989). A hypervariable microsatellite revealed by in vitro amplification of a dinucleotide repeat within the cardiac muscle actin gene. Amer. J. Hum. Genet. 44: 397401.

15. Neve, R. L., Stewart, G. D., Newcomb, P., Van KeUREN, M. L., Patterson, D., Drabkin, H. A., AND KuRnit, D. M. (1986). Human chromosome 21 -encoded cDNA clones. Gene 49: 361-369.

16. RICHARDS, J. E. (1983). Ph.D. Thesis., p.100.

17. ROMMENS, J. H., IANNUZZI, M. C., KEREM, B.-S., DRUMM, M. L., MElmer, G., DEAN, M., RozMahel, R., COLE, J. L., KENNEDY, D., HidAKa, N., Zsiga, M., BuCHWALD, M., RIoRDAN, J. R., TSUI, L.-C., AND CoLLINS, F. S. (1989). Identification of the cystic fibrosis gene: chromosome walking and jumping. Science 245: 1059-1065.

18. SaIKI, R. K., Scharf, S., Faloona, F., Muluis, K. B., HoRN, G., ERLICH, H. A., AND ARNhEIM, N. (1985). Enzymatic amplification of $\beta$-globin genomic sequences and restriction site analysis for diagnosis of sickle cell anemia. Science 230: 1350 1354

19. SOUTHERN, E. M. (1975). Detection of specific sequences among DNA fragments transferred to nitrocellulose. J. Mol. Biol. $\mathbf{9 8 :}$ 503-517.

20. TAYLOR, B. A., AND ROWE, L. (1989). A mouse linkage testing stock possessing multiple copies of the endogenous ecotropic murine leukemia virus genome. Genomics 5: 221-232.

21. VAN PraAgh, R., Layton, W. M., AND Van PraAgh, S. (1980). The morphogenesis of normal and abnormal relationships between the great arteries and the ventricles: Pathologic and experimental data. In "Ftiology and Morphogenesis of Congenital Heart Disease" (R. Van Praggh and A. Takao, Eds.), pp. 271316, Futura, Mt. Kisco, NY.

22. WEBER, J. L., AND MAY, P. E. (1989). Abundant class of human DNA polymorphisms which can be typed using the polymerase chain reaction. Amer. J. Hum. Genet. 44: 388-396. 